\title{
Estudio, restauración y reintegración in situ del mosaico Los amores de Zeus
}

\author{
Ana Bouzas Abad*, Esther Núñez Pariente de León | Centro de Intervención del \\ $\mathrm{IAPH}$ \\ Inmaculada Espinosa Vargas | Técnica en restauración y conservación del \\ patrimonio histórico \\ URL de la contribución <www.iaph.es/revistaph/index.php/revistaph/article/view/4711>
}

\section{RESUMEN}

En el transcurso de unas excavaciones arqueológicas realizadas en la antigua Plaza de Armas del municipio sevillano de Écija se descubrió, en 2015, un magnífico mosaico en el que, entre otras escenas, se representaban varios episodios de la vida amorosa de Zeus. En diciembre de 2017 fue trasladado al taller de material arqueológico del IAPH para su intervención.

Todos los estudios histórico-arqueológicos y análisis practicados han estado destinados a conocer en profundidad el mosaico, así como las causas de su degradación y patologías. Durante el proceso de intervención, se llevó a cabo un tratamiento de restauración-conservación que consistió en devolver a este bien cultural su unidad y correcta lectura, con un respeto absoluto al original.

El objetivo final de esta acción tanto a nivel de investigación, como de restauración-conservación-reintegración, ha sido preservar su integridad en las mejores condiciones posibles y devolverlo, finalmente, a su lugar de origen, logrando con ello una adecuada musealización y transmisión de los valores culturales de los que es portadora la pieza.

\section{Palabras clave}

Arte romano | Bienes muebles | Écija (Sevilla) | Época romana | Indicadores de alteración | Intervención | Los amores de Zeus | Mosaicos | Técnica de conservación | Técnica de consolidación | Técnica de reintegración | Tesela | 


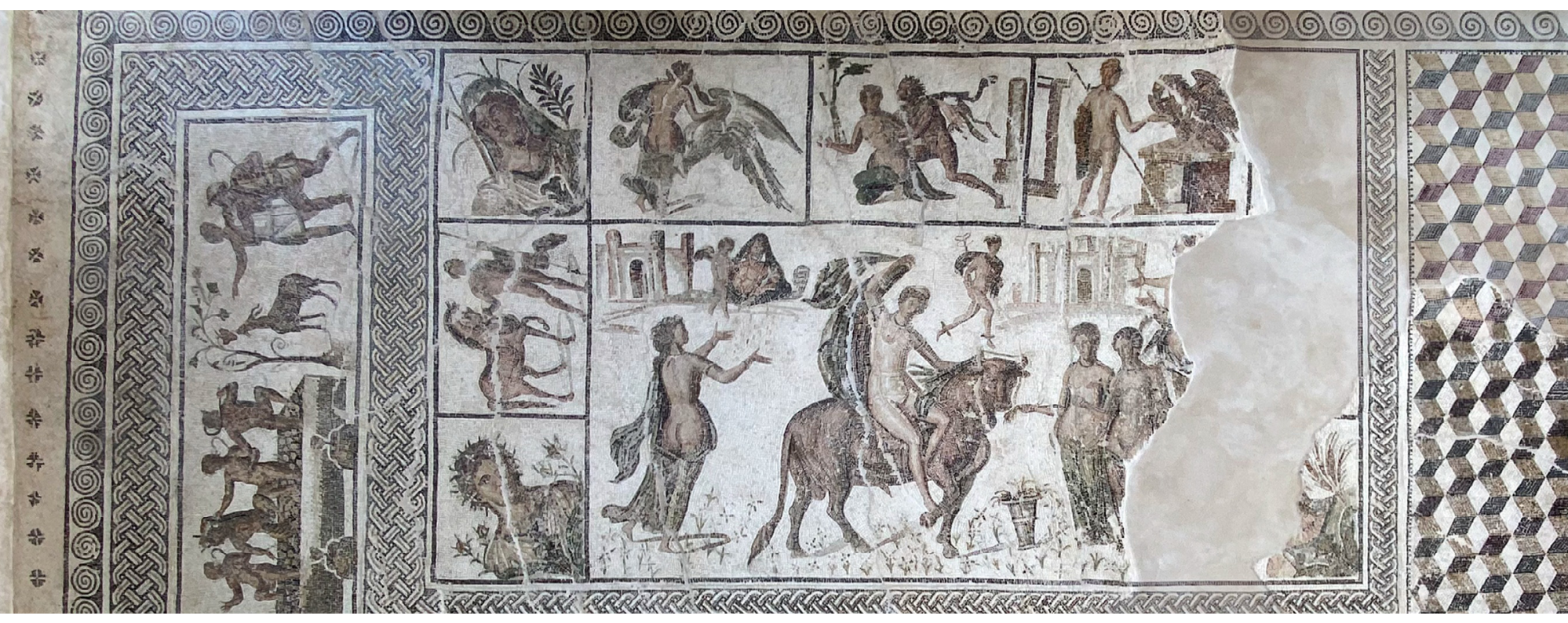

\section{Historical Study, Restoration and Reintegration in situ of the mosaic named Los Amores De Zeus}

\section{ABSTRACT}

During the archaeological excavations carried out in the old Plaza de Armas of the Sevillian municipality of Écija, a magnificent mosaic was discovered in 2015, representing various episodes of Zeus's love life. It was transferred in December 2017 to the Andalusian Institute of Historical Heritage (IAPH) for intervention in the Archaeological Material Workshop.

A restoration-conservation treatment was carried out that consisted of returning to this cultural asset, through historical, scientific and conservative studies, the unity of the mosaic and its correct reading, with absolute respect for the original.

All the studies have been destined to know in depth the causes of the degradation and the pathologies that this mosaic presented. The final objective of this restoration-conservation action has been to return the cultural property to its original place for its proper musealization and the transmission of the cultural values of which this mosaic is the bearer.

\section{Key words}

Roman Art | Movable Cultural Heritage | Écija (Sevilla) | Roman Period | Disturbance Indicators | Intervention | Los amores de Zeus | Mosaics | Conservation technique | Consolidation technique | Reintegration technique | Tile |

Cómo citar: Bouzas Abad, A., Núñez Pariente de León, E. y Espinosa Vargas, I. (2021) Estudio, restauración y reintegración in situ del mosaico Los amores de Zeus. revista $P H$, n. $^{\circ}$ 103, pp. 36-59. Disponible en: www.iaph.es/revistaph/index.php/revistaph/article/view/4711 DOI 10.33349/2021.103.4711

Enviado: 19/06/2020 | Aceptado: 26/03/2021 | Publicado: 10/06/2021 


\section{INTRODUCCIÓN}

En el mes de diciembre de 2017 se depositó este pavimento musivo en el Taller de materiales arqueológicos del IAPH, tras el acuerdo realizado con el Ayuntamiento de Écija que encargó a esta institución la redacción del proyecto de conservación.

El objetivo planteado ha sido el de promover la formulación y/o ejecución de una serie de actividades tecnológicas y de investigación, cuyos resultados han contribuido al avance significativo en el conocimiento del IAPH, en materia de conservación y restauración específica de esta tipología de patrimonio arqueológico y, en consecuencia, progresar en la aplicación de nuevos enfoques o metodologías en revestimientos musivarios que hayan de conservarse y exponerse in situ.

Por otra parte, de forma previa y sincrónica con el proceso de restauración, se han desarrollado los pertinentes estudios de ampliación de conocimiento, al objeto de que las actuaciones conservativas sean consecuentes con las directrices del IAPH, según las cuales "hay que conocer antes de intervenir" y, así mismo, se da cumplimiento a las normas en materia de restauración. Por ello, este artículo se configura no como un estudio monográfico desde la perspectiva arqueológica, sino como la síntesis de los trabajos multidisciplinares efectuados por el equipo técnico del IAPH, sobre este excepcional mosaico romano.

\section{ESTUDIO HISTÓRICO-ARQUEOLÓGICO}

El mosaico se encontró en el cerro de San Gil, popularmente conocido como El Picadero. Se trata del único lugar de la ciudad con una cierta elevación, situación geoestratégica favorable para la formación del primitivo núcleo urbano de la actual Écija, previsiblemente coincidente con la designada en los textos romanos como Astigi Vetus (Plinio, siglo I d. de C.). Esta hipótesis se fue consolidando ya desde el año 1985 cuando, a raíz de unas excavaciones realizadas en la adyacente calle de La Merced, se encontraron estructuras domésticas y materiales muebles correspondientes a los siglos VIII y VII a. de C. Posteriormente, todo este espacio fue amortizado sucesivamente por las distintas culturas que se asentaron en la zona, llegando, sin solución de continuidad, hasta nuestros días.

Durante el pasado siglo, principalmente en su segunda mitad, el área donde se ubicó la Plaza de Armas del alcázar islámico fue ocupada por un urbanismo residual que surgió espontáneamente, sin ningún tipo de planificación. A principios de este siglo, al objeto de erradicar dichas casas -carentes en muchos casos de las instalaciones más necesarias-, se fue trasladando a 
las familias residentes a viviendas sociales, dejando expedito el solar, que conforma un auténtico tell, para acometer las excavaciones arqueológicas.

Fruto de esas investigaciones, se han documentado numerosos restos y depósitos vinculados a las distintas fases de habitación, de suerte que los niveles correspondientes a la etapa romana han entregado óptimos resultados, destacando estructuras adscribibles, principalmente, a lujosas domus. Una de ellas es a la que se llamó del Sátiro Sileno (debido al primer mosaico descubierto en una de sus habitaciones -el tablinum-, que no es otro que el habitualmente denominado como de la Doble Cara) y donde, más tarde (marzo de 2015) aparecería, en una estancia próxima, el mosaico de Los amores de Zeus. Esta nueva habitación -previsiblemente el triclinium- tenía grandes proporciones (7,42-7,91 m de $\mathrm{N}$ a S y 4,62-4,71 m de $\mathrm{E}$ a O) y un único acceso, encontrándose sus paramentos arrasados por las construcciones medievales. En la misma domus, también se han hallado un pavimento de opus sectile y muros con revestimientos parietales magníficamente conservados. Por otra parte, la vivienda se encajaba por todos sus lados dentro del viario romano.

El de Los amores de Zeus (García-Dils de la Vega y Ordóñez Agulla 2019) se concreta en un pavimento de opus tessellatum de forma rectangular y gran tamaño (5 x $8 \mathrm{~m})$, elaborado con una cuidada factura y amplia policromía, proviniendo su denominación de la temática principal representada en los motivos figurados: algunos de los devaneos amorosos del padre de los dioses ${ }^{1}$.

En base a la documentación aportada en su momento por el Servicio de Arqueología del Ayuntamiento de Écija pero, sobre todo, de la correcta visualización que a partir de su restauración pudo hacerse de la pieza (inicialmente, al mantener grandes depósitos de barro y presentar diferentes fracturas, había bastantes detalles inapreciables), la ordenación decorativa del mosaico, del exterior hacia el interior, se describe sintéticamente de la siguiente forma:

Rodeando todo el pavimento, se aprecian diferentes bandas sucesivas de mayor o menor anchura, entre las que se intercalan motivos geométricos variados (roleos, flores cuadripétales, etc.) en colores blanco y negro.

La zona central se adecúa en su morfología a la función que debió cumplir la estancia, de comedor, de suerte que existe un espacio en forma de "L" relleno exclusivamente con motivos geométricos (cubos con juego de colores que les confiere la apariencia tridimensional), que estaría casi totalmente cubierto por los muebles, lo que nos aproxima grosso modo al número y distribución de los lecti y otros enseres domésticos.

En el lateral menor izquierdo aparece, encuadrado por una trenza de cinco cabos, una gran escena de vendimia: a un extremo observamos a la diosa
1

Desde nuestro punto de vista, sería más adecuado utilizar la denominación de dioses y personajes míticos en latín, dado el contexto cultural del mosaico pero, al objeto de no crear confusión, utilizamos en todo caso los nombres en griego con los que han sido designados por los descubridores. 
Gea con una pequeña figura de niño a su lado, que debe tratarse de uno de sus hijos en consonancia con la iconografía más frecuente; al lado contrario vemos representados a dos hombres que posiblemente encarnen a lkarios y al propio Dionisos, como inventor del vino; en el espacio central del tapiz y alineado con el eje longitudinal de la estancia, se dibuja un lagar con cinco figuras masculinas desnudas, una de las cuales representa a un sátiro o al mismo dios Pan; en la parte inferior de la imagen, el mosto cae en sendas dolia. Separando las escenas aparecen una cabra, vides y cestos llenos de racimos y pámpanos.

El sector más importante de la composición -central superior-, queda delimitado del resto del mosaico por filas de teselas bícromas y una trenza de tres cuerdas que se une, en una solución de continuidad perfectamente conseguida, con la trenza más ancha que rodea el panel lateral. El interior de este rectángulo se ocupa con escenas figurativas de carácter mitológico.

En cada esquina se sitúan las alegorías de las estaciones representadas por efigies femeninas de las que emergen motivos vegetales; se conservan las que suponemos simbolizan el invierno y la primavera; el verano está parcialmente destruido y el otoño ha desaparecido completamente.

El resto del panel está relleno por una gran composición separada en cuadros y cerrada al fondo por un horizonte arquitectónico, donde se representan las siguientes escenas relativas a los lances amorosos de Zeus:

$>$ Uno de los Dióscuros con un caballo; suponemos que, para guardar simetría y por tratarse de un tema en consonancia con los amores de Zeus, en la banda opuesta se ubicaría al otro Dióscuro, si bien esta parte del mosaico está destruida.

$>$ Episodio de Leda y el cisne, que se representa en una forma poco convencional ya que la reina está de espaldas, arrodillada frente al cisne que se ve casi de frente; lo acaricia con su mano derecha, mientras que el hombro y brazo izquierdos no son visibles al estar cubiertos por un manto.

> Continúa la narrativa visual con el episodio de Antíope y el sátiro, captado en el instante en el que la ninfa, que está sentada desnuda en posición casi frontal, es sorprendida por la espalda por Zeus convertido en sátiro.

> El rapto de Ganímedes cierra el panel superior. El príncipe troyano se representa casi de espaldas, desnudo con el manto sobre el hombro izquierdo, tocado con gorro frigio y portando una lanza; extiende su brazo derecho hacia el águila que está sobre una especie de ara, con las alas parcialmente abiertas. Este dibujo está afectado, en su ángulo superior derecho, por la gran rotura que ha destruido a otras representaciones cercanas. 
$>$ El mito de Danae y la lluvia de oro se ofrece en este paño en forma poco usual, ya que la princesa argivia se sitúa de pie y de espaldas, recibiendo en sus manos al dios metamorfoseado en monedas aúreas que emanan de una figura piramidal (representación de Zeus como nube); junto a esta aparece un erotes.

$>$ El rapto de Europa, en el centro y a mayor escala, plasmado en el momento en que la princesa tiria epónima del continente, cubierta escasamente por un himation aun sin arquear por el viento, está tranquila (utilización de la forma del mito no violento) subida sobre el lomo del animal, que permanece en tierra pero ya andando; junto a ella figuran dos de sus damas ofreciendo al toro hierba de un cesto. Al fondo, unas construcciones difusas y el dios Hermes.

\section{PARALELOS LOCALES}

Écija es muy rica en patrimonio arqueológico, en general, y en pavimentos musivos, en particular, siendo en torno a 80 los que se han detectado en el transcurso de obras y excavaciones. De entre ellos, son numerosos los que utilizan temáticas similares (asuntos báquicos, las estaciones, amores de Zeus, etc.) al que hemos descrito, de suerte que la comparación morfoestilística, técnica y de diseños ayuda en gran manera a la hora de encuadrarlo cronológicamente, así como a imbricarlo en las corrientes ornamentales y las modas decorativas.

En 1977 apareció un impresionante mosaico en la plaza de Santiago escenificando el Triunfo de Dioniso (Fernández Gómez 1997). A pesar de estar incompleto (sus medidas -las conservadas-son de 7,80 m x 4,20 m, pero se calcula que el pavimento cubriría unos $120 \mathrm{~m}^{2}$ ), se considera uno de los más vistosos de entre los aparecidos en Écija. El mosaico pertenece a la segunda mitad del siglo II d. de C. y la escena, profusa en decoración tanto figurada como geométrica y de vivos colores, gira en torno a un medallón central dibujado con acentuada perspectiva y fuerte movimiento, donde observamos al dios del vino sobre una cuadriga tirada por centauros y, cosa menos frecuente, centauresas; el emblema está rodeado por las alegorías de las estaciones, escenas mitológicas, animales y figuras humanas.

\section{$>$ Triunfo de Baco}

Se encontró en la Avda. Miguel de Cervantes, 22 (Blanco Frejeiro 1952). Con unas dimensiones en lo conservado de $7,20 \times 4,50 \mathrm{~m}$, contiene en el cuadrado central, enmarcado por peltas y amplios sectores con diferentes elementos geométricos, la figuración de un carro al que van uncidos dos tigres, sobre el que se encuentran Dionisio y Ariadna. Destaca el efecto óptico de pliegues y el juego de color en la túnica de Ariadna. 
2

Las fotografías tomadas en la década de los 80 del pasado siglo han perdido, lógicamente, parte de su nitidez debido al proceso de digitalización y, sobre todo, colorido, por lo que, actualmente, no son plenamente representa tivas de la auténtica policromía de los mosaicos

Mosaico del Cortejo Báquico aparecido en calle Espíritu Santo a barrera de Oñate de Écija

Detalle del mismo mosaico. Obsérvese la sensación de movimiento conseguido en la túnica de la ménade | fotos Esther Núñez

\section{$>$ El Cortejo Báquico}

El Cortejo Báquico² (Núñez Pariente de León 1995) se descubrió en el transcurso de una excavación arqueológica realizada entre los años 1990-91, en un solar ubicado en la calle Espíritu Santo a barrera de Oñate, y presenta bastantes similitudes iconográficas con el de Los amores de Zeus. Se trata de una composición muy original que desarrolla, valiéndose de diversas escenas propias del ciclo báquico, el triunfo del niño Dioniso, que se nos presenta con clámide al hombro y tirso en la mano derecha, cabalgando sobre una
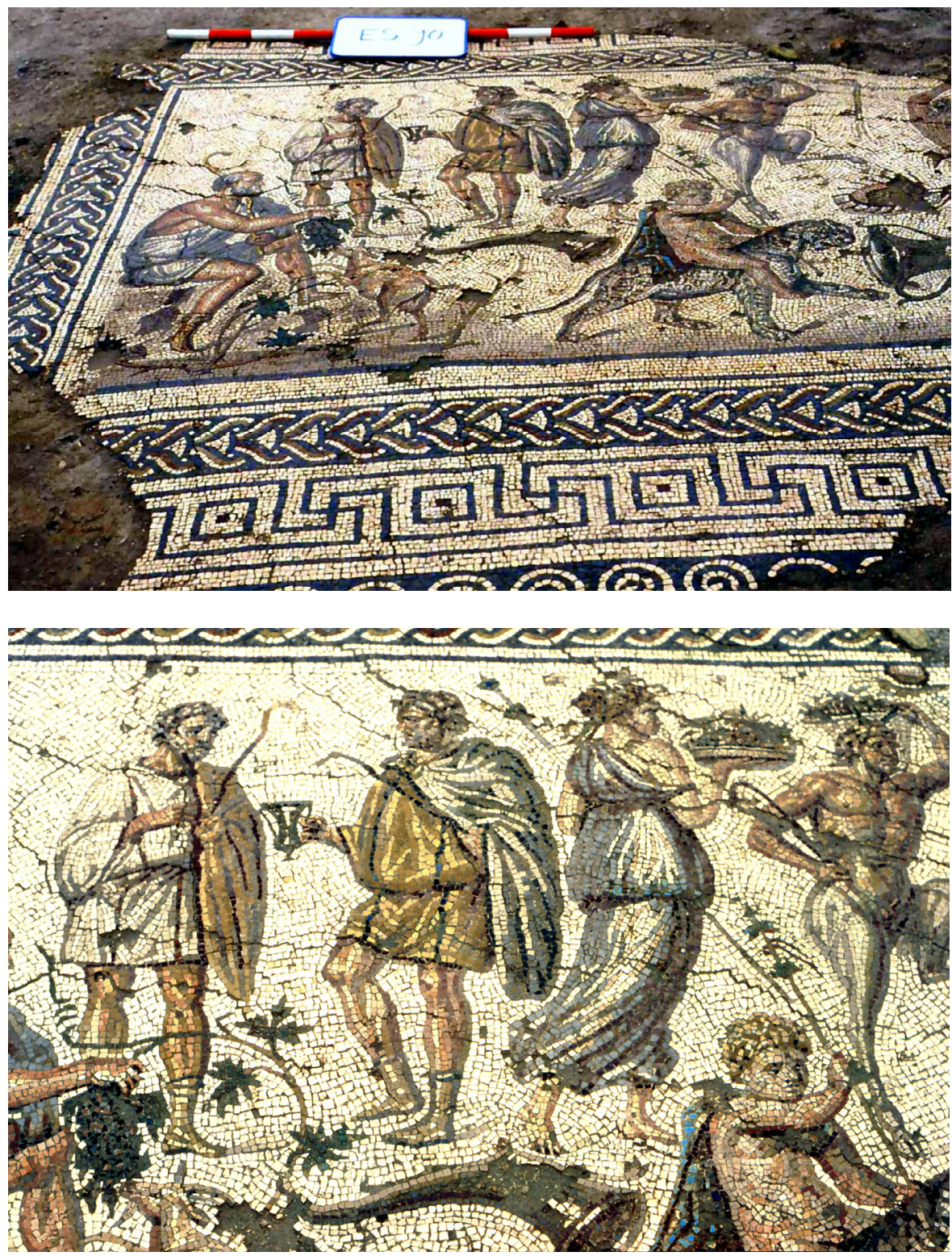
pantera. Distribuidas armónicamente por el pavimento encontramos una alegoría pastoril que representa a un anciano que podría ser Ikarios. Dos hombres supuestamente personajes del cortejo. Una ménade y un sátiro como elementos habituales en un thyasos; de la primera, resaltar la profunda sensación de movimiento de cuerpo y ropajes; del segundo, mencionar que ha sido identificado como una alegoría de Pan. También se plasma la vendimia y el pisado de la uva, con la imagen recurrente del mosto que mana del lagar y cae en los dolia situados más abajo. En el resto del mosaico encontramos objetos báquicos (rython, tiympanos y crátera), así como elementos geométricos (bandas, trenzas, roleos, etc.). En este mosaico hay que destacar, tanto su enorme calidad técnica, como una originalidad única en la composición (Vargas Vázquez, López Monteagudo y García-Dils de la Vega 2017).

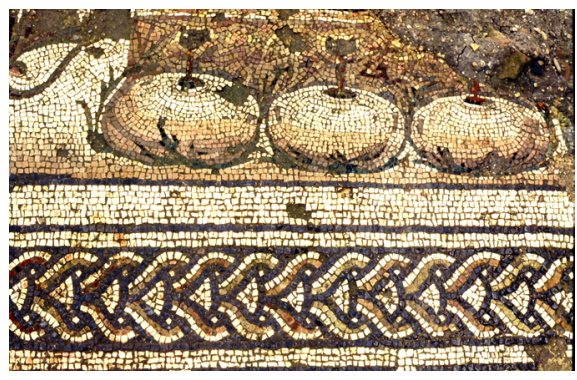

Detalle del mismo mosaico en el que se aprecia una escena similar a la del lagar de Los amores de Zeus: el mosto pisado va cayendo en unos dolia | foto Esther Núñez

\section{$>$ Rapto de Europa}

También encontramos el mosaico del Rapto de Europa (Núñez Pariente de León 1995), magnífica pieza que, lamentablemente, una vez excavada, documentada y protegida, quedó bajo la cimentación de un edificio de nueva planta, de suerte que la información extraída durante el proceso de excavación es la única existente. Encontrado en la misma excavación que el anterior, se halló completo pero algo deteriorado por concreciones y fuertes manchas negras causadas por el incendio o la descomposición orgánica de los sustentantes de la techumbre de la propia domus que cayeron sobre él. Su esquema compositivo es el siguiente: franja de teselas de figlina en disposición reticular seguida de dos filas en situación lineal; a continuación, una banda de $2 \mathrm{~cm}$ en negro; luego otra mucho más ancha $(23,5 \mathrm{~cm})$ en blanco, en la que se insertan peltas en negro, naranja y ocre, de $14 \mathrm{~cm}$ de altura; sigue una nueva línea en negro de $2 \mathrm{~cm}$, otra de $5,5 \mathrm{~cm}$ en blanco, nuevamente una fila de $2 \mathrm{~cm}$ en negro y otra de $4 \mathrm{~cm}$, en blanco, enmarcando ya los motivos figurativos, no solamente en la orla, sino también en las propias formas geométricas donde se sitúan los personajes; sigue una banda negra de $9 \mathrm{~cm}$ donde se dibuja un cuidado sogueado en negro, blanco y ocre/naranja. Los motivos centrales están formados por un círculo de 1,50 $\mathrm{m}$ de diámetro contorneado a cierta distancia (unos $3 \mathrm{~cm}$ ) por una línea de una sola tesela en granate sobre un fondo totalmente blanco. El tema figurativo principal es el del Rapto de Europa. La figura femenina está bastante deteriorada, sobre todo ennegrecida, aunque en lo apreciable parece de una estupenda ejecución y de muy profusa policromía, principalmente en el himation, extendido al viento, que utiliza toda la gama de azules, verdes y turquesas propios de las teselas de pasta vítrea. Se la representa terciada sobre el costado del animal y agarrada a uno de sus cuernos. Sobre ella flota un erotes. El toro levanta las extremidades en actitud de furiosa carrera no obstante hallarse parcialmente sumergido en el agua (parte marítima de la "trilogía" en que se puede dividir el mito en su conjunto) y dibuja bien su anatomía, al haberse utilizado diferentes matices en los colores que consiguen 

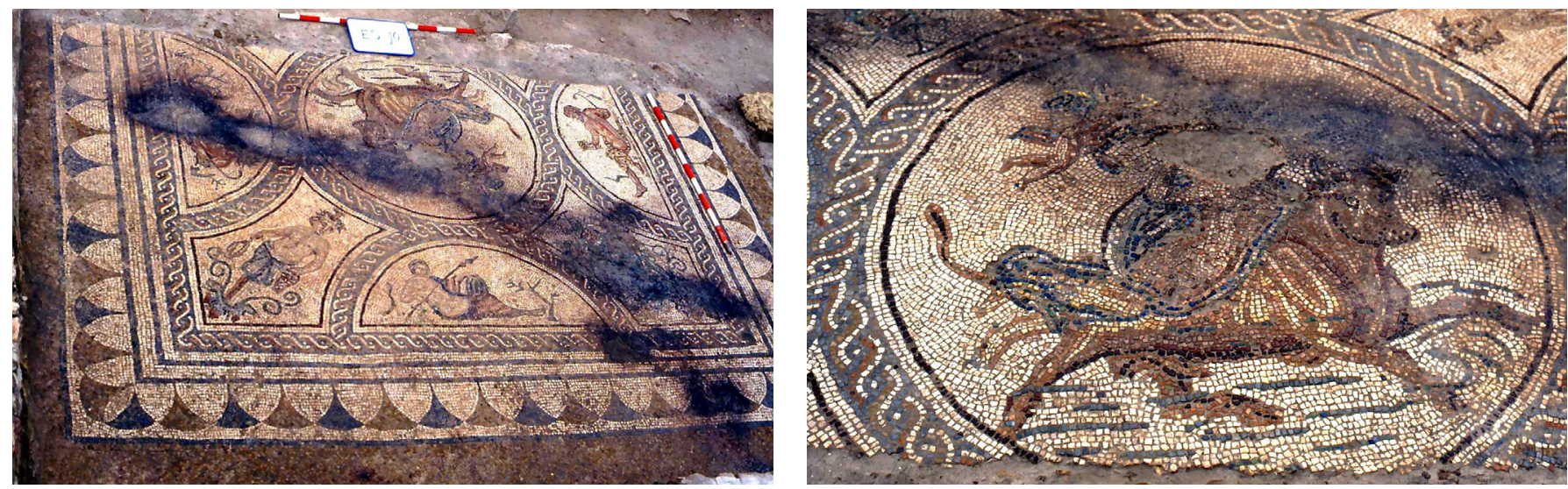

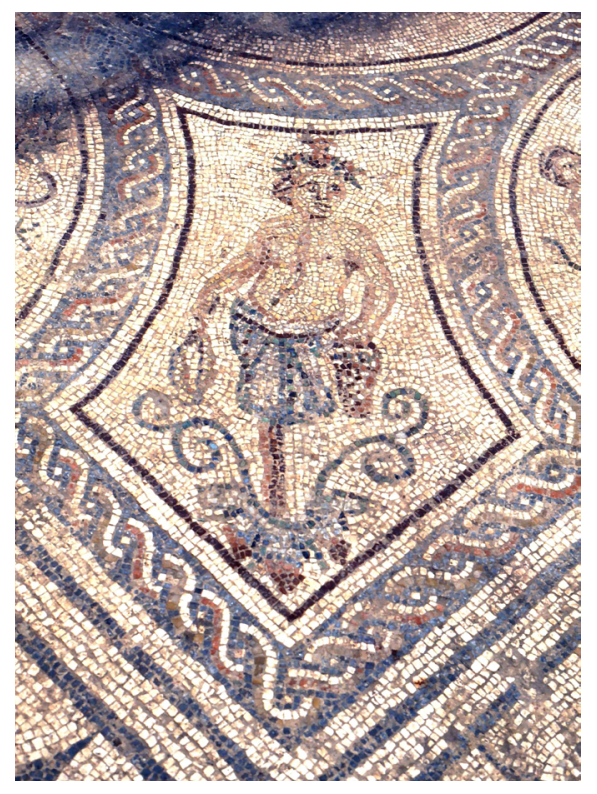

Mosaico del Rapto de Europa de calle Espíritu Santo a Barrera de Oñate de Écija. Arriba a la derecha, se aprecia la escena del Rapto de Europa. Abajo a la izquiera, uno de los hermai del mosaico. En la imagen de al lado, se aprecia cómo la falta de espacio se salva dibujando a la figura recostada fotos Esther Núñez

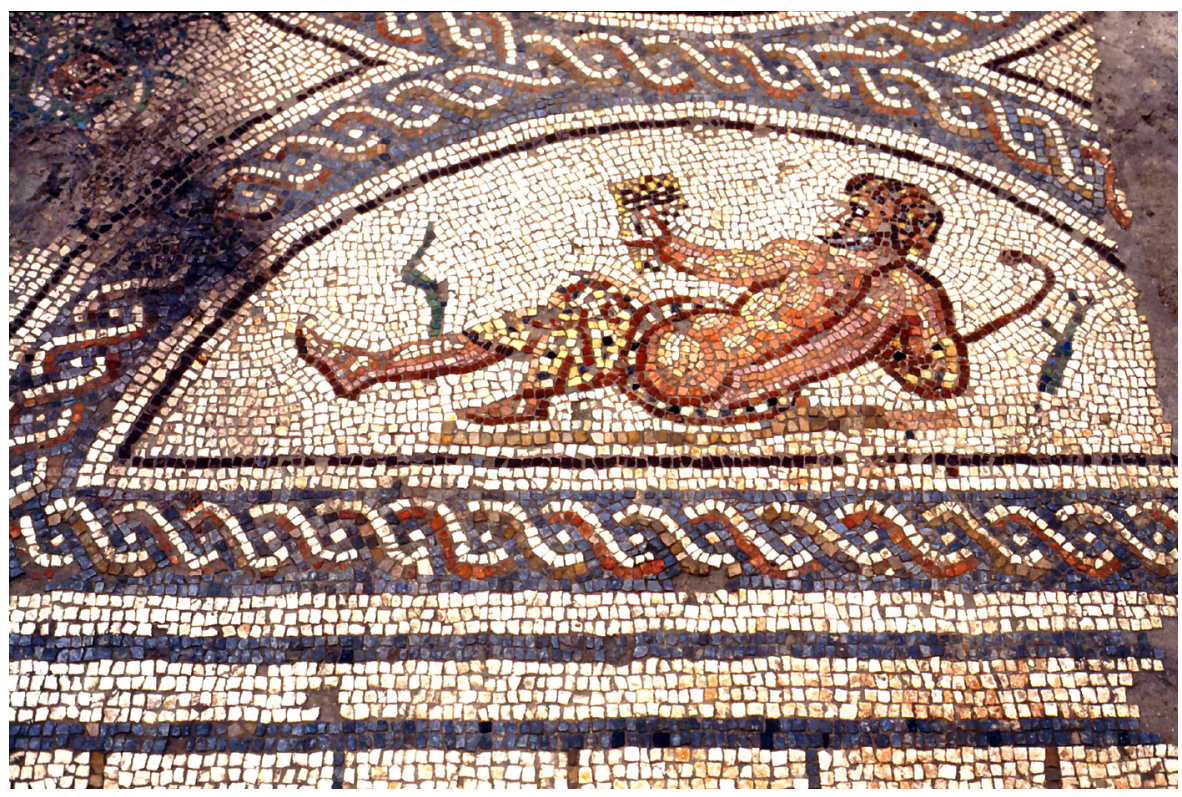

una profunda sensación de relieve. Las figuras laterales, enmarcadas en semicírculos, repiten el mismo esquema que la central: se trata de dos personajes masculinos y uno femenino (falta el cuarto que, suponemos, debería ser también femenino y estar enfrentados dos a dos), en posición reclinada, condición impuesta por el escaso espacio en el que se inscriben; el situado al $\mathrm{S}$ se aprecia muy mal, pero los que están al $\mathrm{N}$ y $\mathrm{O}$ se conservan, por el contrario, en muy buen estado. En las esquinas se dibujan una especie de hermaes emergiendo entre sarmientos de vid y racimos.

$>$ Mosaico de la Doble Cara

En relación con el mosaico llamado de la Doble Cara, más allá del parecido en cuanto a sus representaciones de temática báquica, lo interesante 
es que se encontró muy próximo (Plaza de Armas del alcázar) al mosaico Los amores de Zeus. Su composición consiste en una serie de bandas, cuadros y elementos geométricos concéntricos que enmarcan al panel central. Hay que hacer notar que todo el sector noroeste del mosaico sufrió una restauración de época, tratando de reproducir el mismo esquema compositivo, aunque utilizando una técnica muy tosca; por otra parte, de los cuatro recuadros situados en las esquinas, solo uno (y parcialmente otro) se conserva en buenas condiciones, que representa una máscara de teatro. Respecto al emblema central, está realizado con gran maestría utilizando teselas diminutas (vermiculatum) de piedra y pasta vítrea, y una rica policromía que logra gran efecto volumétrico; dibuja una cabeza masculina de doble lectura, dependiendo del punto de vista del observador: desde el $\mathrm{N}$ de la estancia se puede contemplar a un joven portando un pedum, y desde el S, a un anciano barbado con un tympanum (García-Dils de la Vega, Sáez Fernández y Ordóñez Agulla 2005).

\section{$>$ Mosaicos de C. San Juan Bosco, 8}

En el transcurso de esta excavación se detectaron 9 pavimentos musivos, de entre los cuales dos de ellos presentan temas relacionados: el mosaico $A$ que, aunque bastante deteriorado, en su recuadro central, de unos 2,5 $\mathrm{m}^{2}, \mathrm{y}$ rodeado con profusión de trenzas y cenefas, se pueden observar dos escenas de amores de Zeus. Las figuras que centran la temática son un rapto de Europa, en relativo buen estado, en el que la mujer se presenta recostada sobre el animal, agarrada a uno de sus cuernos (en forma de creciente) y con el velo hinchado por el viento; el toro vuela por encima del mar (fase marítima del mito), en el que se han dibujado varios peces... y, hecho anómalo, la cabeza de un posible fauno de aspecto leonino (vinculación con tema báquico).

La otra representación del emblema consiste en un posible rapto de Ganímedes (aunque también puede interpretarse, a falta de ningún atributo identificativo, como un Eros que impele hacia el océano al toro-Zeus) del que sólo se aprecian las piernas de este y las alas ¿del águila?

Por otro lado, en el mosaico B, aún más deteriorado que el anterior, sólo se conserva como motivo figurativo las patas traseras de un tigre uncido a un carro, lo que nos revierte a un thyasos (Rodríguez Temiño y Núñez Pariente de León 1985).

Como se evidencia por la repetición de modelos, resulta palpable que uno de los temas favoritos en la musivaria astigitana es la relacionada con el mundo dionisíaco. Este motivo iconográfico (cuya utilización masiva se dio en las provincias norteafricanas) se extendió ampliamente, tanto a nivel geográfico (por la práctica totalidad del mundo romano) como cronológico (los triunfos,

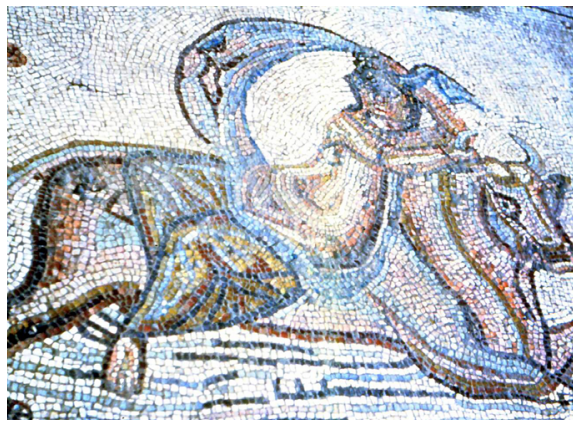

Detalle del mosaico del Rapto de Europa de calle San Juan Bosco, n. 8 de Écija | foto Esther Núñez 
grosso modo, desde el siglo II hasta la finalización del Imperio), si bien tienden a asociarse principalmente a momentos de bonanza social y económica conectando con los sentimientos que llevan a disfrutar de las cosas placenteras. Por ello, el vino y, en su representación Dioniso, tienen una amplia acogida en la Écija de los siglos II y III, etapa en la que la colonia Augusta Firma Astigi consiguió un potente auge económico debido, en buena parte, a sus exportaciones de productos agrarios, sobre todo el aceite.

Por lo que atañe al otro gran tema compositivo del mosaico en cuestión -los escarceos sentimentales de Zeus-, tiene así mismo una amplia dispersión espaciotemporal, sobre todo en lo que a la representación central -el rapto de Europa- concierne, en perfecta consonancia con los temas báquicos, ya que "... en la literatura mistérica Europa es considerada frecuentemente como una bacante, una mystis de los ritos dionisiacos y como una alegoría del alma que avanza por la 'vía de Zeus', por la vía de la salvación del hiero gamos" (López Monteagudo y San Nicolás Pedraz 1995).

Sobre el tercer motivo iconográfico, las estaciones, también existen paralelos en Astigi, siendo el más representativo el llamado mosaico de las Alegorías, que plasma a estas figuras a partir de connotaciones extrapolables de otros casos ya comentados.

Respecto a su cronología, valiéndose exclusivamente de la comparación morfoestilística (no se han publicado ampliamente los datos técnicos de la excavación ni del contexto doméstico del mosaico), es difícil encuadrarlo en una fecha concreta, si bien se han encontrado paralelos astigitanos datados en los siglos II y, sobre todo, III; en este sentido, según los arqueólogos descubridores quienes se basan en el registro material recuperado, se ha fijado en la segunda mitad del siglo II.

\section{ESTUDIO TÉCNICO PARA LA RESTAURACIÓN}

El pavimento fue descubierto por un equipo arqueológico en 2015 en la excavación Plaza de Armas, bajo la dirección del arqueólogo Sergio GarcíaDils de la Vega. Tras su excavación y documentación, fue extraído debido a un deficiente estado de conservación. En ese momento hubo una primera intervención de urgencia que consistió en limpieza y consolidación de ciertas zonas con riesgo de pérdida de teselas, ya que la conservación de la superficie del mosaico no era estable, y presentaba grietas y discontinuidades muy severas.

La actuación que se realizó en el IAPH se basó en el conocimiento del bien cultural para su intervención, conservación-restauración y para volver a colocar el pavimento en su lugar de origen. El estudio científico de los materia- 


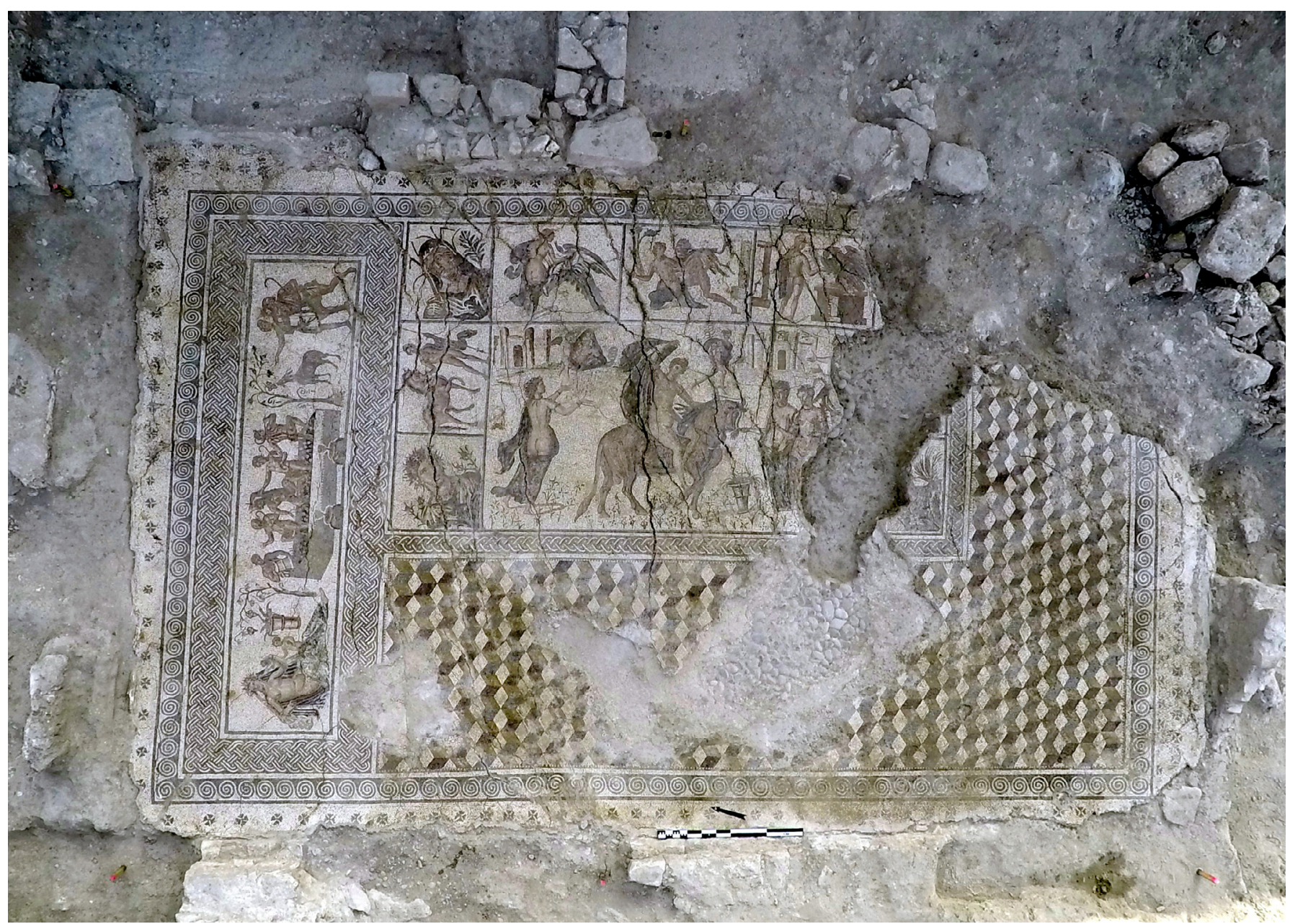

El mosaico in situ después de su excavación. Estado inicial de conservación | foto Sergio García

les que constituyen este bien ha sido necesario y básico para determinar Dils de la Vega las causas que le han afectado en su conjunto. Los estudios históricos, químicos, arqueométricos, petrológicos y biológicos, nos han proporcionado información de la composición cualitativa y cuantitativa de los materiales constituyentes, y del estado de conservación de morteros, de los estratos preparatorios que sustentaban el pavimento, de los materiales pétreos y vítreos utilizados en su decoración, así como los productos utilizados en la extracción e intervenciones precedentes y, por supuesto, los materiales más adecuados y compatibles para su tratamiento y traspaso a un nuevo soporte (Fiori y Vanini 2002; Guichen y Nardi 2008).

El mosaico, de medidas aproximadas de $40 \mathrm{~m}^{2}$, está realizado en opus tesselatum con 30 figuras "dibujadas" con teselas muy pequeñas, de forma muy minuciosa en su representación anatómica y con gran calidad técnica en su ejecución. A nivel cromático es muy espectacular, como se ha mencionado 


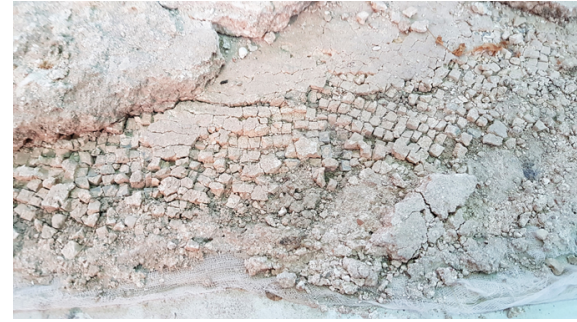

Reverso del mosaico donde se ven las diferentes capas preparatorias | foto Fondo Gráfico IAPH (Ana Bouzas Abad) en el estudio arqueológico, ya que se utilizaron diferentes piedras marmóreas y calizas, de muchos colores y matices, y pasta vítrea para aquellos tonos que no se encuentran en la naturaleza.

Esta técnica musiva empieza a perfeccionarse en la época griega helenística, llegando a crear obras con temas complejos y episodios de la vida cotidiana y de la mitología. Los mosaicos son considerados como una obra pictórica construida de piezas de piedra con forma poliédrica, y cuya ventaja es su gran durabilidad. Surge este procedimiento como una idea para decorar los pavimentos de las estancias más importantes de las viviendas (villas y domus romanas).

El proceso de elaboración de un pavimento musivo se dividía en varias fases, independientes entre sí, que justifican la presencia de un equipo agrupado en un taller, y que necesitaba la especialización de sus miembros en cada etapa del trabajo. Para iniciar la ejecución de un mosaico y antes de colocar las teselas que dibujan el tema elegido, había que preparar bien el suelo. Este soporte debía ser plano, sólido y nivelado para que fuera estable, lo que requería gran pericia, experiencia y habilidad, ya que era muy importante conseguir una superficie lisa y homogénea, con una inclinación suave y calculada que facilitase el deslizamiento del agua hacia los sumideros.

En general el soporte preparatorio suele estar formado por las siguientes capas (Vitruvio; Plinio):

> Statumen: es la primera capa, compuesta por un conglomerado de piedras o fragmentos cerámicos, sobre el suelo natural de tierra.

$>$ Rudus: segunda capa preparatoria, normalmente formada de tres partes de piedra triturada, fragmentos cerámicos y una de cal.

$>$ Nucleus: tercera capa preparatoria, con la misma composición que la anterior, pero más fina.

> Cama: es la última capa sobre la que se insertan las teselas, consistente en un mortero fino rico en cal.

Este mosaico ha sido realizado siguiendo este precepto. Lógicamente el statumen no se transportó con los fragmentos, pero se observaba en el rudus los negativos de las piedras de base. El nucleus era de entre 3 y $3,5 \mathrm{~cm}$ de grosor, y la composición de ambos estratos era de cal y guijarros triturados de distinta volumetría, de una gran dureza y resistencia. Por último, la cama es de un espesor muy variable, según la zona: en los diseños geométricos y zonas monocromas era muy fina, mientras que en las figuras era un poco más gruesa. 
Los morteros estaban compuestos, en rudus y nucleus, por cal aérea con agregados locales y contenido arcilloso, además de aditivos puzolánicos y fragmentos cerámicos que se añadieron a los estratos del pavimento. Se destacó en el nucleus un contenido importante de estos aditivos que explican su mayor dureza y compacidad. Estos mismos fragmentos cerámicos fueron utilizados para la elaboración de teselas. Una vez construida esta base se aplica la cama, de mortero rico en cal, donde se van a posicionar las teselas. Es entonces cuando se traslada a esta capa el diseño del mosaico: cenefas, roleos, motivos vegetales, figuras, etc., que decoran la superficie.

Paralelamente a la fabricación del soporte, se iban cortando las teselas en cuadrados de diferentes tamaños, sobre un yunque u otro elemento de apoyo, dependiendo de su ubicación. La medida de las teselas que componen el fondo y los motivos geométricos oscila entre 0,5 y $1 \mathrm{~cm}$. Las que forman parte de las figuras son mucho más pequeñas y van entre los 0,2 y 0,3 cm. En este pavimento se han contabilizado aproximadamente unas 100 teselas por 10 $\mathrm{cm}^{2}$. Los materiales pétreos utilizados han sido calizas de diferentes colores (grisácea, negro, blanco, rosácea, amarillenta, rojiza, rojo oscuro), mármol de color gris y blanco, y también materiales cerámicos de color anaranjado. Las teselas vítreas son de color: verde, azul y negra, todas ellas en diferentes tonalidades de grises, azulados, turquesas y algunas transparentes.

Para la disposición de las teselas sobre el mortero primero se trazaban los contornos de los motivos y posteriormente se rellenaban con ellas dibujando las formas. Para las alineaciones de teselas del fondo, se utilizaban clavos con cuerdas. Todo ello se ajustaba y nivelaba mediante un martillo de madera hasta dejar la superficie completamente plana. Por último, se aplicaba en la superficie un mortero fino compuesto por polvo de mármol, arena y cal para rellenar todas las juntas, y dejarla compacta y resistente.

\section{ESTADO DE CONSERVACIÓN}

El estado de conservación del mosaico no era bueno por la poca cohesión y estabilidad que presentaban las capas base. En ello ha influido no sólo la degradación natural de los materiales que lo componen, sino también el enterramiento, las condiciones ambientales, las modificaciones por distintas ocupaciones e intervenciones, zanjas modernas, movimientos del terreno, etc. Todo ello ha ocasionado abundantes deformaciones en el pavimento, con la consiguiente pérdida de teselas. Además, tenía numerosas e importantes grietas. Las capas de preparación (rudus y nucleus) estaban decohesionadas, fracturadas y friables. Los morteros de preparación de estas mismas capas no tenían una buena adherencia entre ellos. La cama, compuesta de cal aérea con agregados de cuarzo, es de gran porosidad y muy fina, lo que explica el alto número de teselas despegadas.

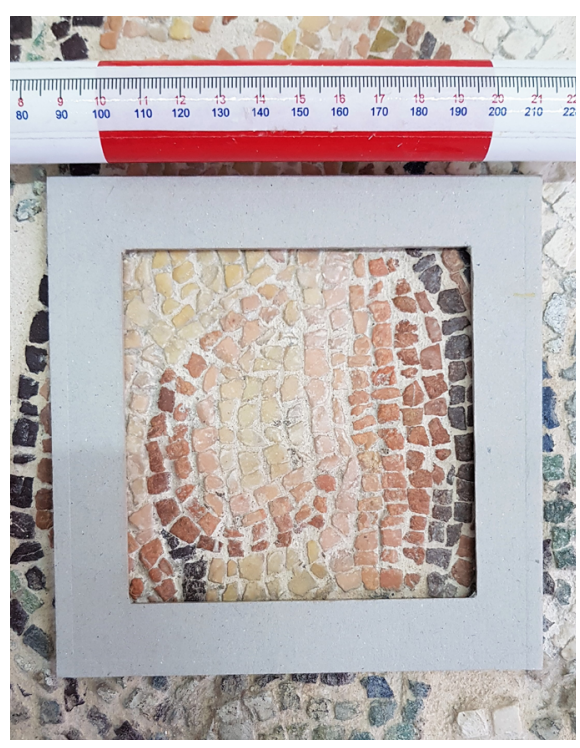

Porcentaje de teselas utilizadas en $10 \mathrm{~cm}^{2}$ en motivos figurativos y animalísticos

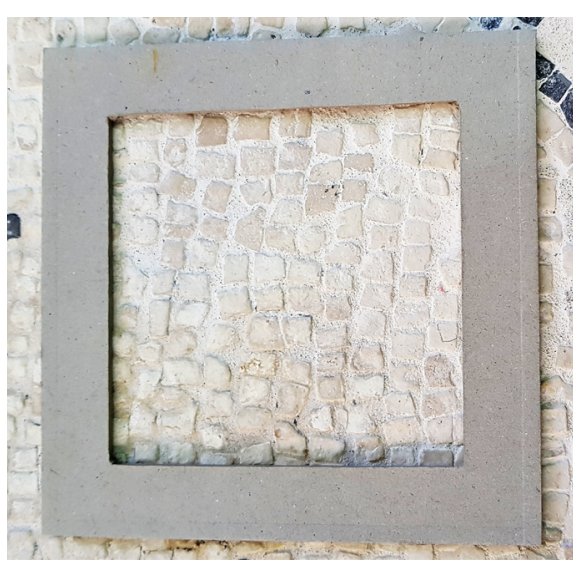

Porcentaje de teselas utilizadas en $10 \mathrm{~cm}^{2}$ en motivos geométricos y fondo del mosaico | fotos Fondo Gráfico IAPH (Ana Bouzas Abad) 
Los problemas que se han encontrado en el proceso de restauración responden a errores en la técnica de ejecución del pavimento cuando se hizo el mosaico en el siglo III d. de C. (IAPH 2019a).

Otro factor importante en su estado de conservación ha sido la metodología empleada para la extracción aprovechando las grietas naturales que tenía el pavimento y se extrajo en 30 fragmentos, por ello los tamaños de las placas son tan dispares y algunos demasiado grandes para su manipulación. Se efectuó también una consolidación puntual con gasa, por el peligro de desprendimiento de teselas, y un engasado de la superficie para realizar el arranque, utilizando para ambos tratamientos la misma resina acrílica a muy alta proporción, lo que fue contraproducente a la hora de retirar estas protecciones, ya que el disolvente utilizado para quitar las gasas despegaba a la vez la consolidación puntual de las teselas.

Cuando se inició el tratamiento por el reverso se constató que además de la mala conservación de los morteros, los fragmentos presentaban abundantes zonas desagregadas, con grietas, fisuras, microfisuras y grandes aportaciones de barro. Igualmente, abundantes teselas perimetrales se habían despegado de la gasa de extracción, por envejecimiento de la resina aplicada. Por el anverso, muchos fragmentos presentaban microorganismos en la gasa, alteración que indicaba problemas de humedad durante el almacenaje, hecho que favoreció el estado de pudrición de algunas gasas. Los restos de tierra y de barro que no se eliminaron de la superficie musiva antes de su engasado para el arranque estaban consolidados por la resina acrílica (IAPH 2019c).

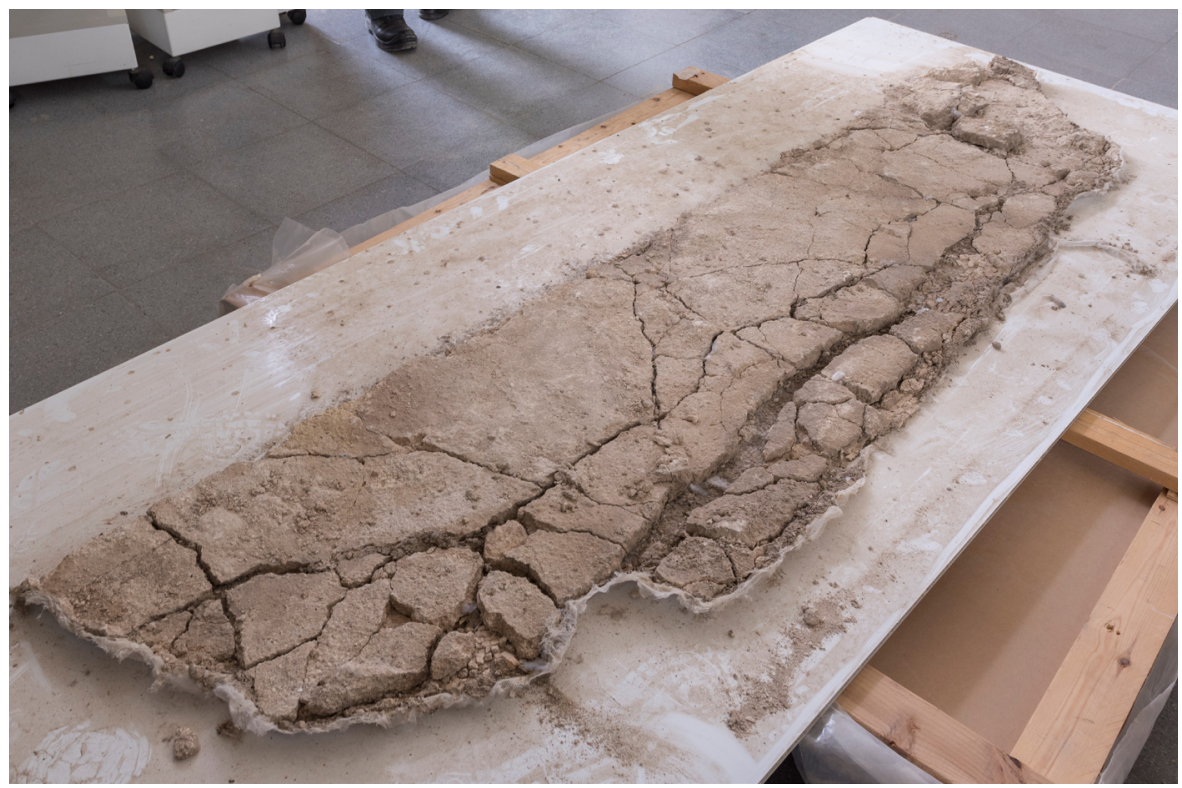




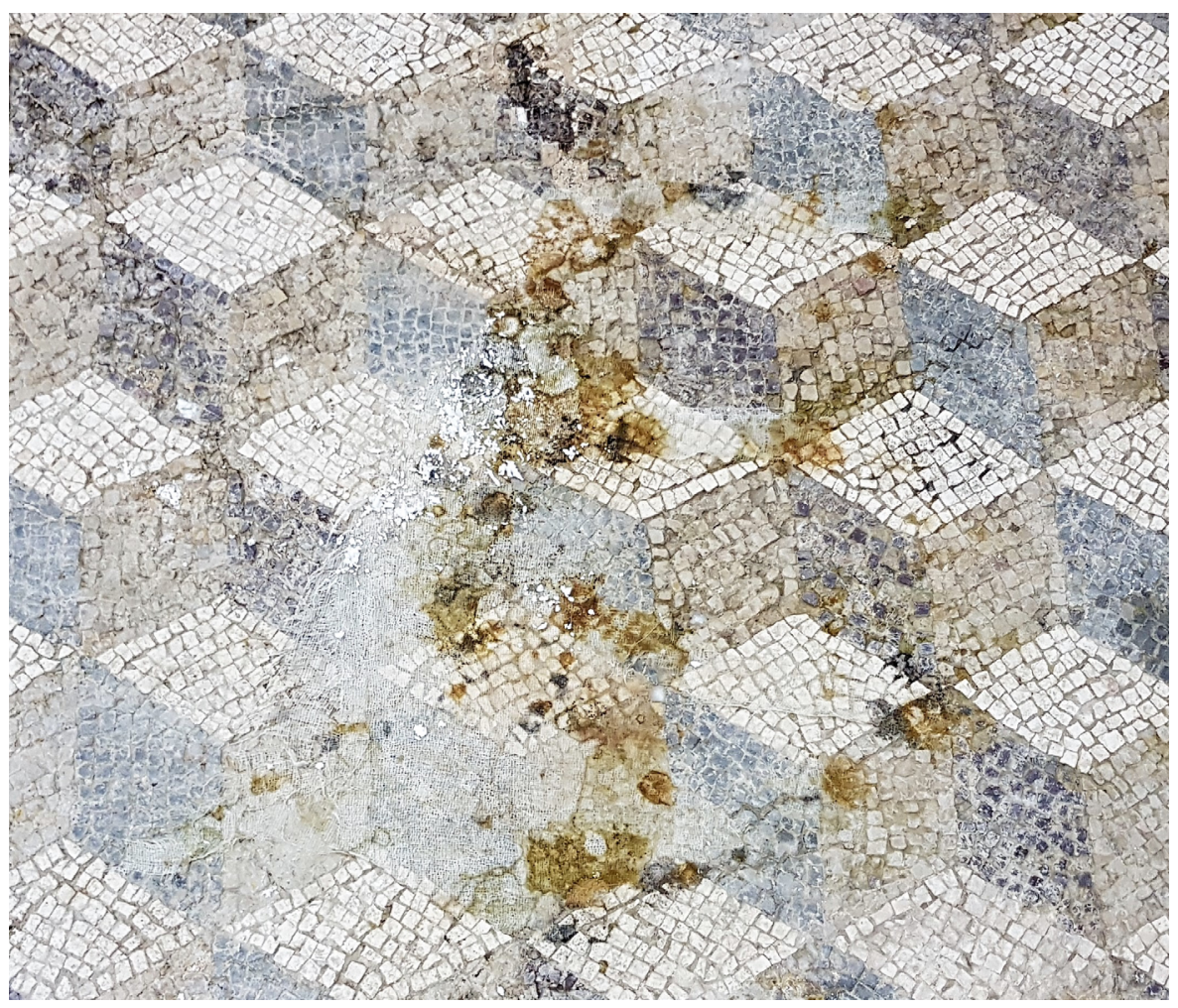

Las teselas pétreas presentaban alteraciones en diferentes grados como: fracturación, disgregación, erosión, exfoliación, etc. Las más dañadas eran las de color ocre y granate, y las de pasta vítrea estaban especialmente degradadas. El estudio científico por microscopía óptica demostró que todas las teselas presentaban un porcentaje importante de alteraciones de carácter medio o avanzado, como picaduras concoidales, descamaciones, corrosión iridiscente y presencia de agentes biológicos (IAPH 2019b). Por último, también se han encontrado zonas de concreciones y manchas de carácter férreo sobre las teselas, provocadas por objetos de hierro en contacto con la superficie del mosaico durante su enterramiento.

\section{METODOLOGÍA Y CRITERIOS DE INTERVENCIÓN}

El concepto actual de conservación-restauración de bienes culturales se concibe como una disciplina más especializada, que aplica medidas de tipo científico y conservativo, ambas dirigidas, a conocer en profundidad las causas de degradación y las patologías presentes, para que la intervención directa sobre el bien sea restringida al mínimo indispensable. Los condicionantes que reúne esta obra han exigido una intervención de gran complejidad a nivel conceptual. Para ello, un equipo interdisciplinar (formado por restauradores,
Ciertos fragmentos presentaban microorganismos en la gasa, alteración que indicaba problemas de humedad durante el almacenaje | foto Fondo Gráfico IAPH (Ana Bouzas Abad) 
historiadora, técnico de imagen, químico, petrólogo y técnico en conservación preventiva) ha evaluado las posibilidades de actuación de acuerdo con los principios de estabilidad, reversibilidad, discernibilidad y legibilidad, en el marco de los criterios vigentes en materia de conservación-restauración.

Para ello se efectuaron los estudios preliminares y simultáneos a la intervención para "conocer antes de intervenir", y así detectar y eliminar los factores de deterioro que, directa o indirectamente, incidieron en el estado de conservación del bien, definiendo los materiales a emplear para que respondiesen a las necesidades conservativas de la obra, documentando todas y cada una de las etapas de la intervención, para así devolver la unidad a la obra y su correcta lectura, con un respeto absoluto al original, sin falsear ni añadir.

El hallazgo de un pavimento musivo en un yacimiento arqueológico siempre ha representado un gran problema en la toma de decisiones, entre su extracción y cambio de ubicación, descontextualizándolo de su entorno original, o su conservación in situ. En este caso la finalidad de esta intervención ha sido el de devolver el bien cultural a su lugar original para su correcta musealización y trasmisión de los valores culturales de los que es portador.

Los criterios de actuación seguidos durante la intervención han sido:

$>$ Restauración integral de todos los fragmentos del mosaico, para que en la fase de montaje in situ recupere su aspecto formal y funcional.

> Suprimir las capas preparatorias del soporte original (los morteros no estaban en buen estado de conservación) hasta llegar a la cama donde se asientan las teselas. Sobre esta capa original aplicar un mortero compatible y de las mismas características, cal y arena, que servirá como estrato intermedio para la adhesión de un soporte inerte, rígido y ligero, que suplirá la función del antiguo.

$>$ Durante el proceso de intervención las teselas despegadas de cada fragmento se posicionan en él, y se llevan a su lugar por medio de la documentación fotográfica existente. Las teselas descontextualizadas se utilizan para el relleno de las pequeñas lagunas o para coser/unir los fragmentos durante el montaje in situ.

$>$ El criterio para la reintegración de lagunas y grietas es arqueológico, consistente en rellenar a bajo nivel, con mortero de cal y arena, las lagunas y grietas, que quedan como testimonio de los movimientos del terreno y argumentan su historia material. No se insinúa ni se completa ninguna forma figurativa porque no hay documentación en la que basarse. Con este criterio se consigue restituir una continuidad estructural y la importancia/esencia de la obra. 


\section{TRATAMIENTO}

La intervención comenzó por el reverso, desbastando y enrasando por medios mecánicos los morteros originales que presentaban grandes discontinuidades y estaban frágiles y decohesionados, llegando hasta la cama, donde van insertas las teselas. Posteriormente se eliminó el polvo con brochas suaves y aspirador. Así se identificaron claramente las grietas que tenía cada fragmento y se pudieron limpiar las teselas que estaban mezcladas con el barro y consolidadas a este por la resina que había penetrado por el engasado del anverso. Paralelamente a esta actuación, se iban consolidando las teselas que se movían utilizando una resina acrílica. En zonas puntuales fue necesario utilizar morteros de cales naturales y exentas de sales eflorescentes, que fueron disueltas en agua desmineralizada y aplicadas mediante inyección. En los bordes de los fragmentos hubo que eliminar meticulosamente el barro consolidado, ya que las teselas presentaban gran inestabilidad.

La corrección de las discontinuidades fue de gran importancia para el futuro montaje, ya que los fragmentos extraídos trasladaban los desniveles y deformaciones del suelo del yacimiento. Al retirar los morteros en mal estado, se pudieron corregir. Como capa intermedia y para homogeneizar toda la superficie se aplicó una capa de mortero de cal y arena (mortero de cal en pasta con arena fina de sílice), y una malla de fibra de vidrio. Este estrato es fundamental para favorecer la reversibilidad del tratamiento, ya que podría ser sacrificado en una futura intervención. Para favorecer la carbonatación del mortero de cal, es importante respetar su secado durante un periodo mínimo de 28 días.

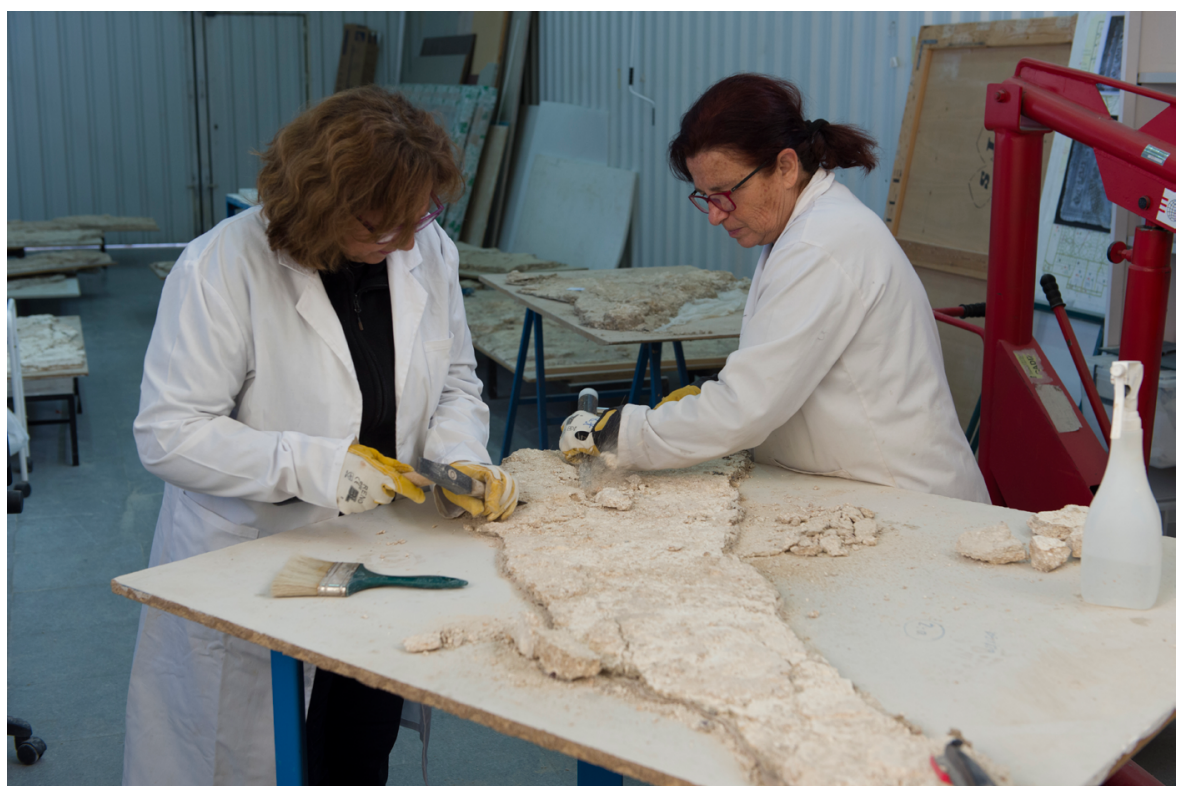

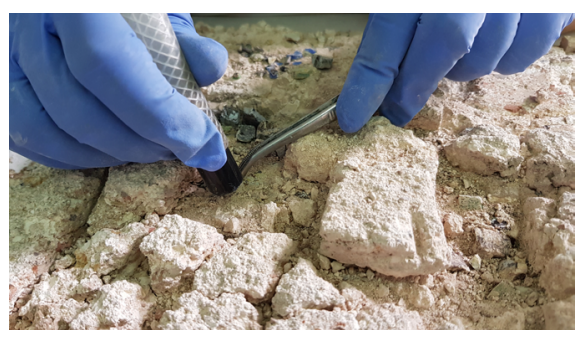

Proceso de aspiración puntual y colocación de teselas sueltas en sus sedes originales

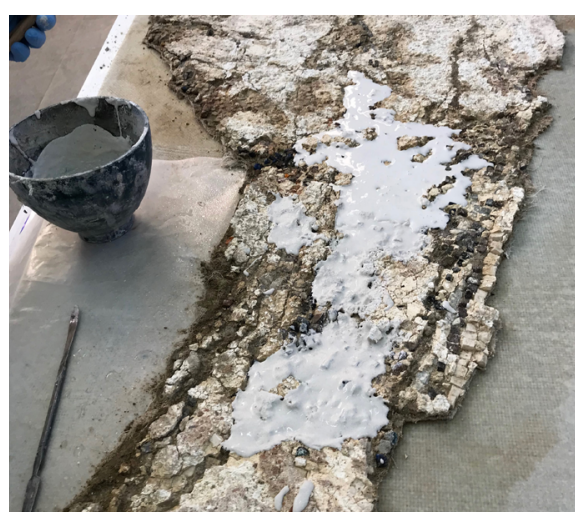

Consolidación del reverso de los fragmentos del pavimento musivo con cales naturales

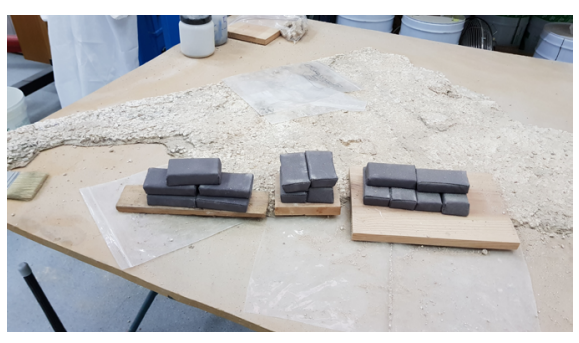

Corrección de deformaciones/discontinuidades de los fragmentos con pesos puntuales | fotos Fondo Gráfico IAPH (Eugenio Fernández Ruiz)

Tratamiento del reverso enrasando los morteros originales mecánicamente | foto Fondo Gráfico IAPH (Eugenio Fernández Ruiz) 
Arriba a la derecha, aplicación de capa de mortero de cal y arena en todos los fragmentos del pavimento; debajo, refuerzo de los fragmentos con varillas de fibra de vidrio corrugado; debajo a la derecha, estabilización con soporte inerte de fibra de vidrio y aluminio adaptado al perímetro de cada pieza | fotos Fondo Gráfico IAPH (Eugenio Fernández Ruiz)

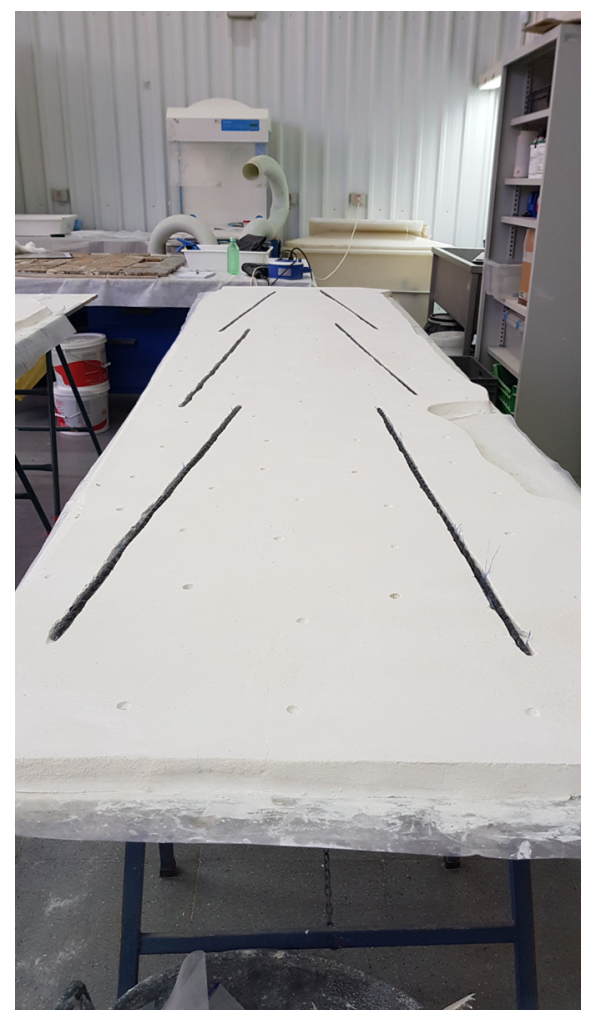

Dada la gran dimensión de algunas placas, se decidió la colocación de varias varillas corrugadas de fibra de vidrio de 4 y $8 \mathrm{~mm}$, para fortalecer los soportes. Para ello, se realizó un cajeado en la superficie del mortero de nueva factura donde se introdujeron las varillas fijándolas con resina epoxi bicomponente.

Se dibujaron en calcos los perímetros de los fragmentos para trasladarlos a un soporte inerte de nido de abeja de aluminio que se utiliza como base aislante, pues aporta resistencia, durabilidad y rigidez. Para unir el nuevo soporte al mortero se utilizó un adhesivo epoxídico tixotrópico, que se caracteriza por tener una estructura con óptima resistencia mecánica.

Finalizada la intervención por el reverso y recuperada la estabilidad de los fragmentos con el nuevo soporte se iniciaron los tratamientos por el anverso. El proceso de quitar las gasas para su extracción fue particularmente difícil por el exceso de resina acrílica aplicada en el momento de la extracción. Una vez retirado el engasado se limpió la superficie con acetona, para eliminar los restos de residuos arcillosos e incrustaciones terrosas consolidadas por la propia resina. Las manchas localizadas por contacto de algún material férreo enterrado junto al mosaico se retiraron con tratamiento químico, aplicando papetas de celulosa de papel impregnadas con una solución química (sal bisódica en agua desmineralizada). Para la limpieza final se realizó un
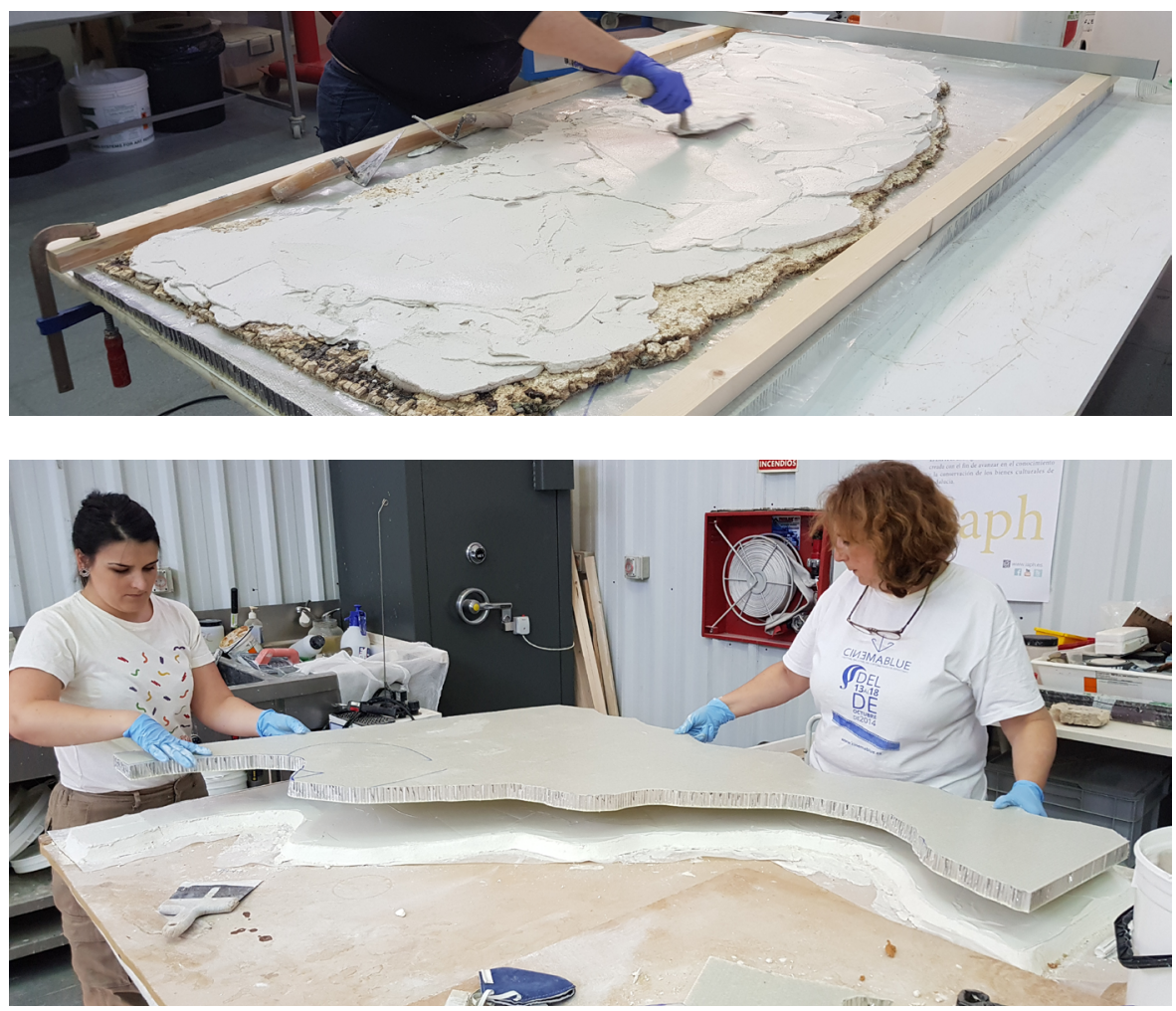

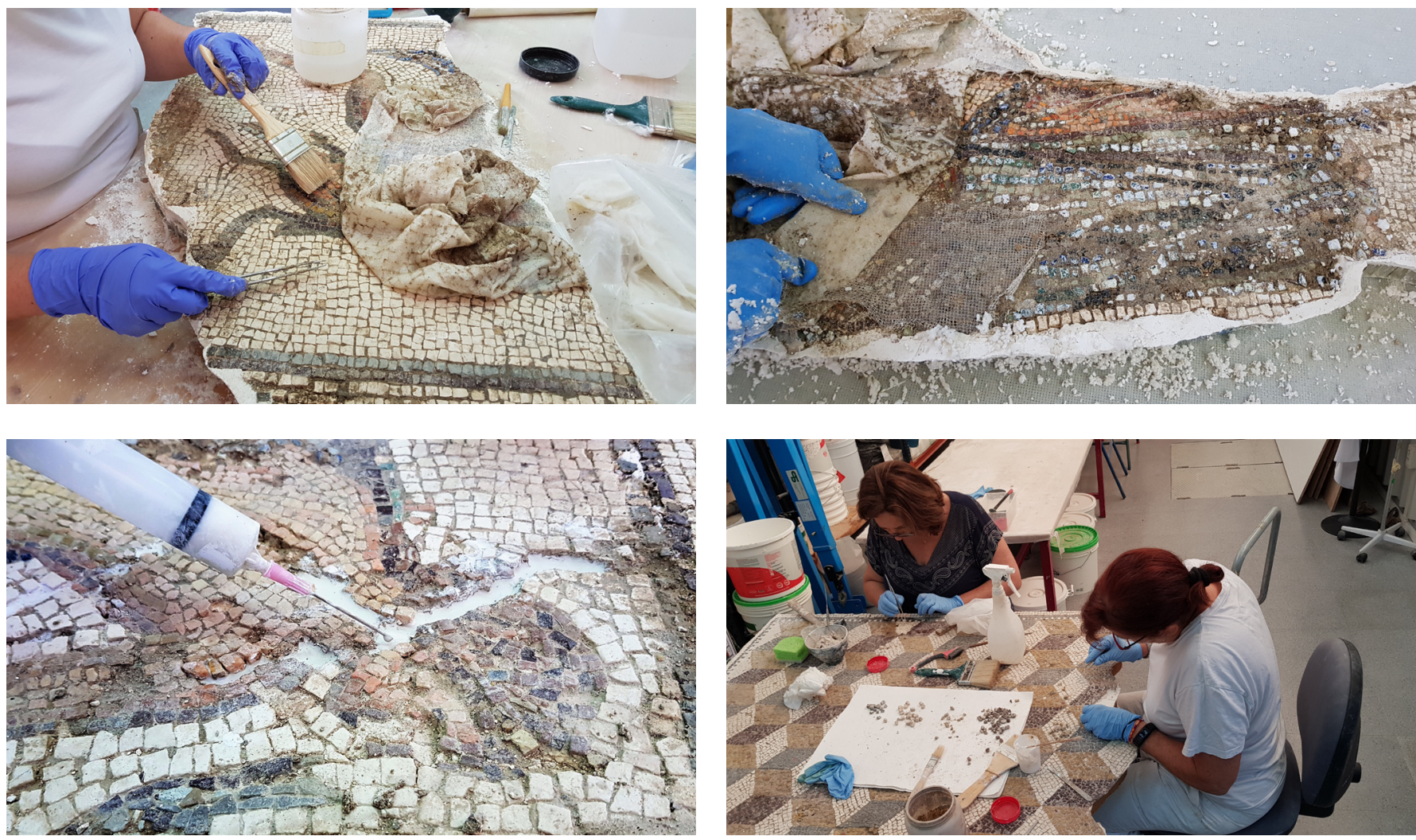

Arriba a la izquierda, retirada de las gasas de protección del anverso con disolventes cetónicos; a la derecha, eliminación de restos de gasas de protección y de tierras compactadas; abajo a la izquierda, consolidación por inyección de cales naturales en grietas y fisuras de pequeño tamaño; a la derecha, reintegración con teselas originales lavado superficial con agua desmineralizada y desinfectantes con propiedades biocidas.

Las teselas despegadas o desubicadas se etiquetaron en bolsas, se limpiaron de concreciones y restos de mortero, utilizando para ello agua desminede las laguna | fotos Fondo Gráfico IAPH (Eugenio Fernández Ruiz) ralizada al $1 \%$ de jabón neutro tensioactivo no iónico. La conservación de todas estas teselas ha sido muy importante ya que se han empleado en el montaje para coser las uniones entre fragmentos.

Con el objetivo de asegurar el buen asentamiento de las teselas más inestables, se consolidaron de forma puntual inyectando con resina vinílica para quedar sujetas a la cama original de mortero de cal. Las vítreas se consolidaron con una resina acrílica en acetona. Para dar firmeza y estabilidad al pavimento, se rellenaron todas las juntas entre teselas con mortero coloreado con pigmentos naturales.

A fin de unificar estéticamente los bordes de los fragmentos se aplicó este mortero coloreado cubriendo los tres estratos: superficie de teselas, capa intermedia de mortero y plancha de material inerte. En la reintegración de las pequeñas lagunas se utilizaron las teselas descontextualizadas, y para relle- 
Consolidación de la superficie musivaria | foto Fondo Gráfico IAPH (Eugenio Fernández Ruiz)

\section{EQUIPO TÉCNICO}

Centro de Intervención y Centro de Inmuebles, Obras e Infraestructuras del IAPH

\section{Raniero Baglioni, conservación preventiva}

Ana Bouzas Abad, conservación y restauración

Inmaculada Espinosa Vargas y

May Espejo Delgado, conservación y restauración

Eugenio Fernández Ruiz, fotografía Auxiliadora Gómez Morón, estudios químicos

Víctor Menguiano Chaparro, estudios biológicos

Esther Núñez Pariente de León, estudios histórico-arqueológicos Esther Ontiveros Ortega, estudios geológicos

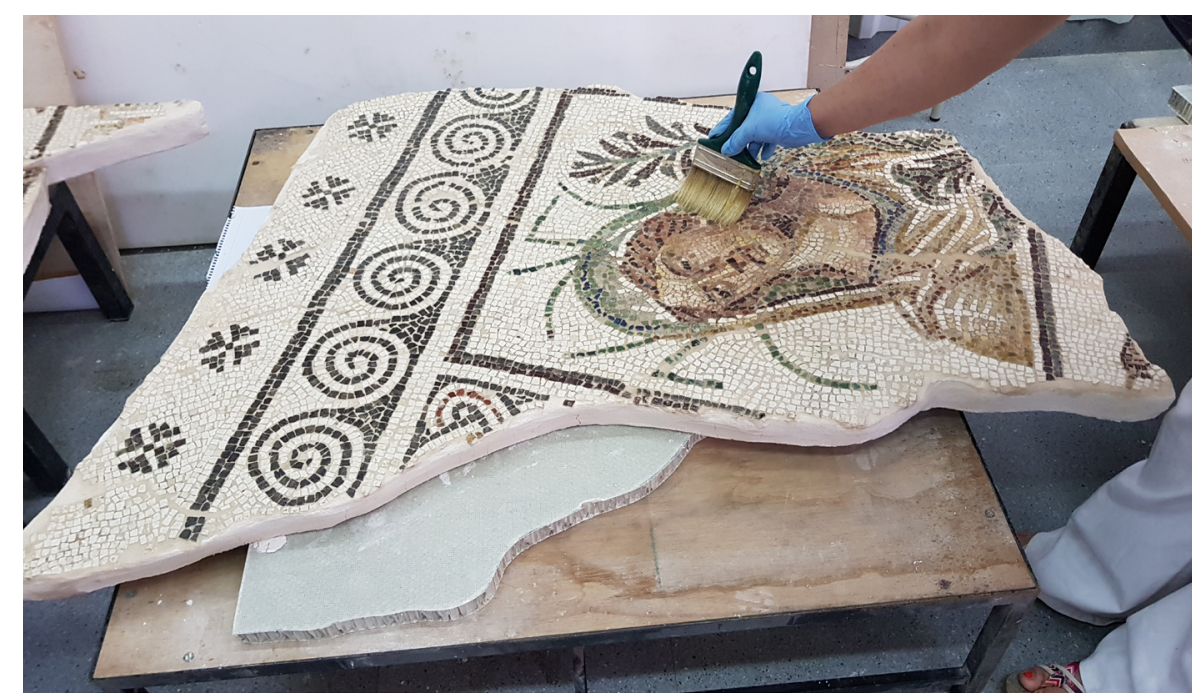

nar las lagunas de mayor tamaño se aplicó mortero con criterio arqueológico, unos milímetros por debajo de la superficie original. Finalmente, se procedió a la aplicación del consolidante en toda la superficie musiva. Para ello se seleccionó un producto basado en silicato de etilo, particularmente indicado para el tratamiento de materiales pétreos.

\section{MONTAJE IN SITU}

El montaje in situ comenzó a finales de octubre de 2019 acondicionando la zona de donde se había extraído el mosaico. Estos trabajos fueron acometidos por técnicos del Ayuntamiento de Écija. En primer lugar, se protegió con una cobertura provisional y luego se habilitó el terreno donde se iban a ensamblar los 30 fragmentos. Se dispuso una capa de arena del triclinium lavada para que las piezas asentasen correctamente. Para homogeneizar la superficie del mosaico y rellenar las grandes lagunas, se aplicó una capa de mortero de cal y arena, y posteriormente una segunda más fina a bajo nivel.

Cuando el mortero estuvo seco se recuperaron los dibujos geométricos: cenefas, cubos, flores e hileras de teselas calcando los motivos originales del propio mosaico, utilizando materiales compatibles y reversibles para su integración cromática.

En este proyecto de conservación-restauración se han cumplido los objetivos planteados: primero recuperar la solidez y estabilidad del pavimento, su unidad estética, su interpretación y entidad. Segundo, colocar el mosaico en su lugar de origen para integrarlo dentro del conjunto arqueológico, y garantizando su protección, mantenimiento y correcta musealización. 

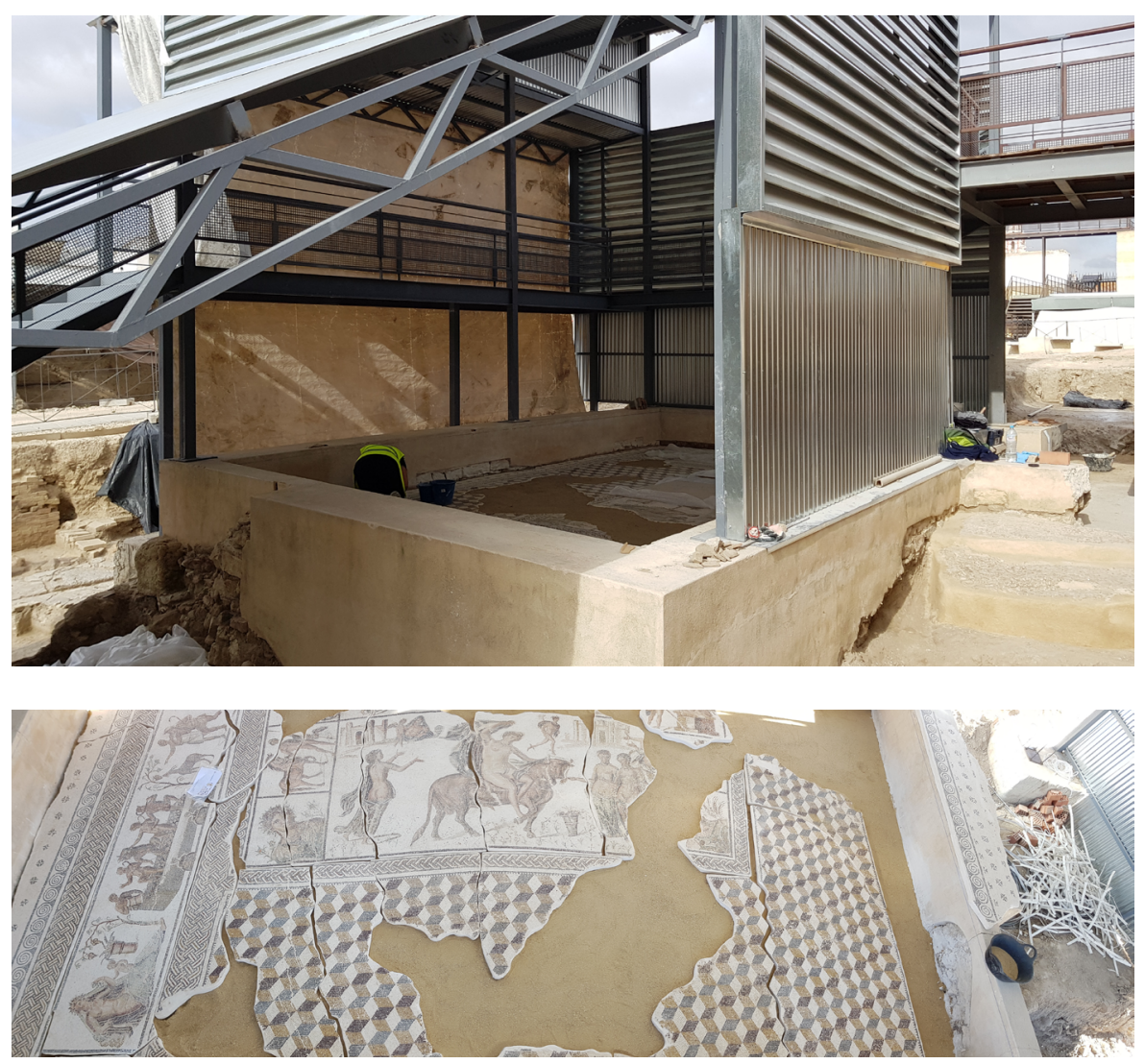

Estructura metálica construida en la ubicación original para la protección del mosaico

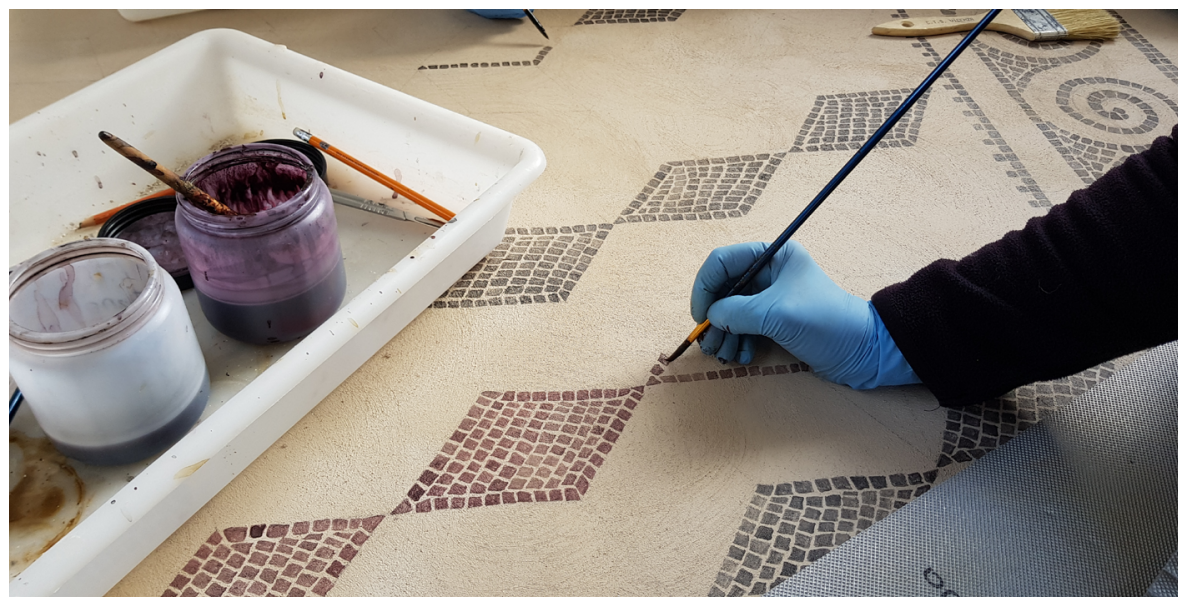

Colocación de los fragmentos en el Triclinium, espacio que previamente fue habilitado para el correcto asentamiento de las 30 piezas musivas

Reintegración cromática de las lagunas con dibujos geométricos | fotos Fondo Gráfico IAPH (Ana Bouzas Abad)

Con la intervención de conservación-restauración en este bien arqueológico, se ha hecho posible la reinstalación del mosaico en la zona arqueológica de la que provenía. Para ello se han seguido las pautas metodológicas y técnicas requeridas al caso, especialmente las exigentes recomendaciones internacionales y las buenas prácticas que se aconsejan en la materia. 


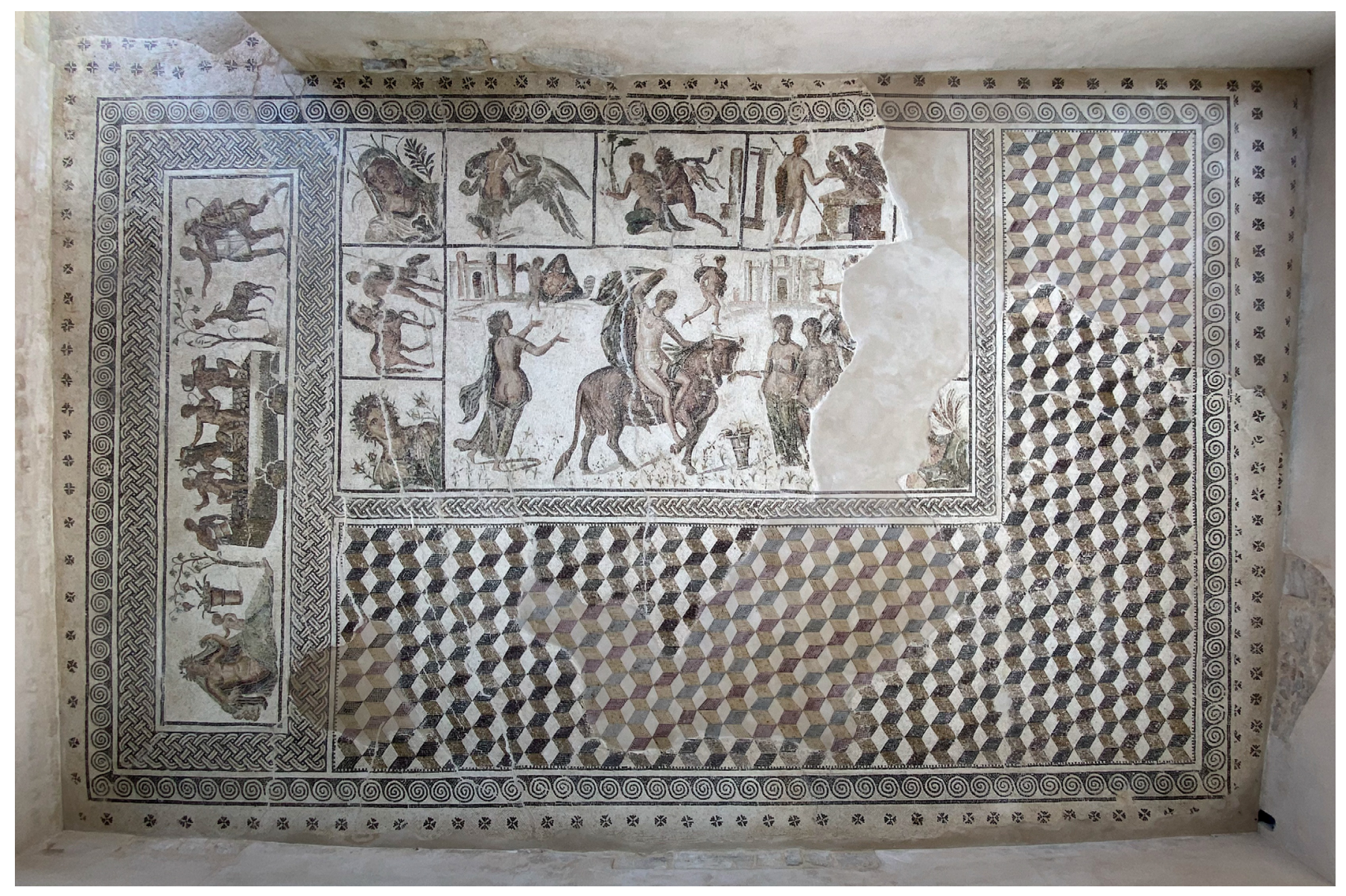

Vista general del mosaico una vez acabado el tratamiento y montaje | foto Sergio García Dils de la Vega

Agradecimientos:

Al Ayuntamiento de Écija; a Sergio García Dils de la Vega, arqueólogo director de los trabajos en el yacimiento Plaza de Armas; y a los participantes en Formación para el empleo del Ayuntamiento de Écija. 


\section{BIBLIOGRAFÍA}

- Blanco Frejeiro, A. (1952) Mosaicos antiguos de asunto báquico. Madrid: Impr. y Editorial Maestre, pp. 29-41

- Fernández Gómez, F. (1997) Excavaciones de urgencia del Museo Arqueológico de Sevilla en la ciudad de Écija. Boletín de la Real Academia de Ciencias, Bellas Artes y Buenas Letras "Luis Vélez de Guevara”, n. ${ }^{\circ}$ 1, pp. 75-97

- Fiori, C. y Vanini, M. (2002) Teoria e tecniche per la conservazione del mosaico. Padova: II Prato

- Guichen, G. (de) y Nardi, R. (2008) Mosaic conservation: fifty years of modern practice. En: Proceedings of the IX Conference of the International Committee for the Conservation of Mosaics, ICCM, Hammamet, Tunisia, Nov 29-Dec 3, 2005. Los Angeles: The Getty Conservation Institute, pp. 9-14

- García-Dils de la Vega, S. y Ordoñez Agulla, S. (2019) El mosaico de los amores de Zeus de la Plaza de Armas de Écija. Écija: Real academia de Ciencias, Bellas Artes y Buenas Letras "Luis Vélez de Guevara"

- García-Dils de la Vega, S., Sáez Fernández, P. y Ordóñez Agulla, S. (2005) Motivo iconográfico excepcional en un mosaico báquico de Astigi (Écija, Sevilla). Habis, n. ${ }^{\circ}$ 36, pp. 389-406

- García-Dils de la Vega, S. (2016) Colonia Avgusta. Firma Astigi. La evolución urbana de Écija desde la Protohistoria hasta la Antigüedad tardía. Sevilla: Universidad de Sevilla

- IAPH [Instituto Andaluz del Patrimonio Histórico] (2019a) Análisis arqueométrico. Pavimento musivo de "Los amores de Zeus" Écija (Sevilla). Anónimo. Siglo II-III d.c. Literatura gris

- IAPH [Instituto Andaluz del Patrimonio Histórico] (2019b) Caracterización de los vidrios del pavimento musivo "Los amores de Zeus" Écija (Sevilla). Anónimo. Siglo II-III d.c. Literatura gris

- IAPH [Instituto Andaluz del Patrimonio Histórico] (2019c) Estudio microbiológico. Pavimento musivo de "Los amores de Zeus" Écija (Sevilla). Anónimo. Siglo II-III d.c. Literatura gris

- León Alonso, P. (2010) Arte romano de la Bética. Mosaicos. Pintura. Manufacturas. Sevilla: Fundación Focus-Abengoa, 2010

- López Monteagudo, G., M. y San Nicolás Pedraz, P. (1995) El mito de Europa en los mosaicos hispanoromanos. Análisis iconográfico e interpretativo. Espacio, tiempo y forma, serie II, Historia Antigua, n. ${ }^{\circ} 8$, pp. 383438. Disponible en: http://revistas.uned.es/index. php/ETFII/ article/view/4272 [Consulta: 30/03/2021]

- Núñez Pariente de León, E. (1995) Informe preliminar de la I.A.U. realizada en la calle Espíritu Santo a barrera de Oñate de Écija, Sevilla. Anuario Arqueológico de
Andalucía/1993 III. Sevilla: Dirección General de Bienes Culturales, Consejería de Cultura de la Junta de Andalucía, pp. 683-695. Disponible en: https://juntadeandalucia.es/ export/drupaljda/1993_URGENCIAS_web.pdf [Consulta: 29/03/2021]

- Plinio el viejo, Naturalis historia, III, 12

- Plinio el viejo, Naturalis historia, XXXVI,186-187

- Rodríguez Temiño, I. y Núñez Pariente de León, E. (1985) Arqueología Urbana de Urgencia en Écija (Sevilla), 1985. Anuario Arqueológico de Andalucía/1985 III. Sevilla: Dirección General de Bienes Culturales, Consejería de Cultura de la Junta de Andalucía, pp. 316-325. Disponible en: https://juntadeandalucia.es/export/drupaljda/1985 ACTIVIDADES_DE_URGENCIAS_web.pdf [Consulta: 30/03/2021]

- Vargas Vázquez, S., López Monteagudo, G. y García-Dils de la Vega, S. (2017) Mosaicos romanos de Écija (Sevilla). Madrid: Consejo Superior de Investigaciones Científicas; Real Academia de Ciencias, Bellas Artes y Buenas Letras Luis Vélez de Guevara (Corpus de Mosaicos Romanos de España, n. ${ }^{\circ}$ 14)

- Vitruvio, De Architectura, VII.I 